\title{
LUT
}

University

\section{Normalization-Based Approach to Electric Motor BVR Related Capacitances} Computation

Ahola Jero, Muetze Annette, Niemelä Markku, Romanenko Aleksei

This is a Final draft

version of a publication

published by IEEE

in IEEE Transactions on Industry Applications

DOI: $10.1109 /$ TIA.2019.2898850

Copyright of the original publication: (C) 2019 IEEE

Please cite the publication as follows:

Ahola, J., Muetze, A., Niemelä, M., Romanenko, A. (2019). Normalization-Based Approach to Electric Motor BVR Related Capacitances Computation. IEEE Transactions on Industry Applications, vol. 55, issue 3. pp. 2770-2780. DOI: 10.1109/TIA.2019.2898850

This is a parallel published version of an original publication.

This version can differ from the original published article. 


\title{
Normalization-Based Approach to Electric Motor BVR Related Capacitances Computation
}

\author{
J. Ahola ${ }^{\dagger}$, A. Muetze ${ }^{\ddagger}$, M. Niemelä ${ }^{\dagger}$, and A. Romanenko ${ }^{\dagger}$ \\ †Department of Electrical Engineering \\ Lappeenranta University of Technology \\ P.O. Box 53851 Lappeenranta \\ Finland \\ \$Electric Drives and Machines Institute \\ Graz University of Technology \\ Inffeldgasse 18, A-8010 Graz \\ Austria
}

\begin{abstract}
Electrical discharge machining (EDM) bearing currents that may occur within electric machines of variablespeed-drive motor systems have been recognized for a long time. One key influential factor, the machine's capacitive voltage divider "bearing-voltage-ratio" BVR strongly depends on the rotor-to-frame and the stator winding-to-rotor capacitances; these are, in turn, affected by the design of the machine's stator slot. This paper presents an approach to improve the accuracy with which these capacitances can be estimated. It is based on the well-known plate capacitance equation which is then corrected by normalization functions. The functions are defined by extensive parameter studies using electrostatic FEM simulations. The final expressions not only allow for the prediction of the statorwinding-to-rotor and rotor-to-frame capacitances, they are also readily applicable. Thereby, they facilitate, for example, the clear-cut study of the sensitivity of the BVR towards changes in the different stator slot parameters.
\end{abstract}

Keywords-bearing currents, electric machine, modelling, variable-speed drive.

\section{INTRODUCTION}

\section{A. Motivation}

$\mathrm{T}$ HE phenomenon of inverter-induced bearing currents that may cause unexpected breakdowns in variablespeed-drive (VSD) systems has been well-recognized and widely studied (e.g., [1]-[9]). Various types of bearing currents with different cause and effect chains can be distinguished from each other, with electric discharge machining (EDM) bearing currents being one of them. The main causes of EDM currents have been understood and modeling approaches at different system levels have been proposed. This includes, for example, the mineral oil behavior under electric discharges [10], estimation of the capacitance formed by the hydrodynamic lubrication areas of the bearings [11], [12], impedances of full bearings [13]-[15], mechanical models of bearings [16], modeling of the capacitances [17], [18] and equivalent circuits of the assembled system [12], [19], [20]. However, techniques to correctly determine the model parameters are still much needed.

\section{B. Contribution of the Paper}

The so-called "bearing-voltage-ratio" (BVR) describes the ratio of the voltage occurring across the bearing and the common mode voltage at the stator terminals. Apart from a machine's operating speed, the BVR is the most important parameter related to the electric machine itself that determines the occurrence of EDM bearing currents and their characteristics (notably amplitude). Therefore, further improvement in the accuracy with which the BVR can be predicted, notably during the design process of the machine, directly addresses the aforementioned need to refine the modeling parameters. In our work, we focus on non-salient machines with distributed windings. The underlying method itself may, however, be subsequently applied to other types of machines, notably to concentrated windings.

\section{Starting Point}

The BVR is mainly determined by the capacitances between the rotor and the frame, $C_{\mathrm{rf}}$, and the winding and the rotor, $C_{\mathrm{wr}}$. The stator slot dimensions significantly affect the values of these two capacitances. The capacitances of the bearings depend on the machine's operating point of, notably its load, temperature, and rotational speed (e.g., [13]-[15], [21], [22]). In contrast, $C_{\mathrm{rf}}$ and $C_{\mathrm{wr}}$ are determined within the overall design process of the electric machine, and are independent of the supply frequency at which the machine operates. Many factors will eventually determine the design of the slots and their openings. However, the availability of advanced modeling techniques, such as those proposed in this paper, will eventually allow for the consideration of the resulting BVR of the final machine design within the design process.

\section{Overwiew of Proposed Approach}

The starting point for the proposed physics-based approach to calculate $C_{\mathrm{wr}}$ and $C_{\mathrm{rf}}$ of machines with distributed windings is the well-known analytic parallel-plate capacitance equation. In contrast to the previous work, this paper proposes consideration of the non-idealities due to the inhomogeneous electric field around the stator slot opening, both in the calculation of the rotor-to-frame and the stator-winding-torotor capacitance, by empirically obtained normalization

(C) 2019 IEEE. Personal use of this material is permitted. Permission from IEEE must be obtained for all other uses, in any current or future media, including reprinting/republishing this material for advertising or promotional purposes, creating new collective works, for resale or redistribution to servers or lists, or reuse of any copyrighted component of this work in other works. 
functions, $k_{\mathrm{rf}}$ and $k_{\mathrm{wr}}$, respectively. The former is a function of the (magnetic) air gap $d_{\mathrm{ag}}$ and of the width of the stator tooth $w_{\mathrm{s}}$. The latter is a function of the distance of the stator winding from the rotor surface $d_{\text {tot }}$ and of the slot opening width $w_{\text {so }}$. These functions are defined by extensive parameter studies using electrostatic FEM simulation to analyze different stator slot designs. The theoretical work is verified experimentally for electric machines of various sizes.

The proposed approach establishes direct relationships between important design parameters of the machine and the capacitances of interest. The final expressions not only allow for the prediction of $C_{\mathrm{wr}}$ and $C_{\mathrm{rf}}$, but also for the straightforward study of, e.g., the sensitivity of the BVR towards changes in the stator slot's various parameters.

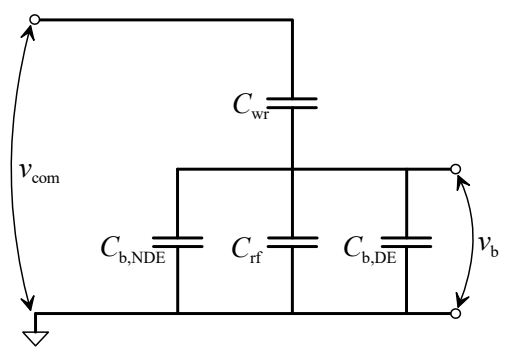

Fig. 1. Established equivalent circuit for the determination of the bearingvoltage-ratio (BVR) in electric machines.

\section{E. Organization of Paper}

The paper is organized as follows: Firstly, Section II shortly presents the BVR model, as it is commonly used today, and identifies the important roles of $C_{\mathrm{wr}}$ and $C_{\mathrm{rf}}$ with respect to the BVR. Subsequently, Sections III and IV review the previously proposed models to compute these capacitances for nonsalient machines with distributed windings and discuss the new normalization function based approaches presented herein, for each of the two capacitances, respectively. Next, Section $\mathrm{V}$ presents the results of the FEM analysis and the derivation of the normalization functions, from both simulated and measured data. Section VI describes the experimentally based part of the research program, using four different induction machines as example case applications. This does not, however, limit the applicability of the proposed method to other non-salient rotating field machines with distributed windings, such as the widely used surface mounted permanent magnet synchronous machines. In Section VII the prosed approach is applied exemplary to parameter sensitivity studies. Finally, the paper closes with some conclusions presented in Section VIII.

\section{BEARING-VOLTAGE-RATIO}

As per its definition, the BVR determines the ratio of the voltage across the bearing, $v_{\mathrm{b}}$, and the common mode voltage at the stator terminals, $v_{\text {com, }}$ as it results from the capacitive voltage divider given by capacitances within the electric machine [5]. The BVR takes on the simplified assumption of a capacitive voltage divider that is considered frequency independent over the range of possible switching frequencies as they occur with variable-speed drives (Fig. 1). It consists of $C_{\mathrm{wr}}, C_{\mathrm{rf}}$, and the two bearing capacitances both on the driveend, $C_{\mathrm{b}, \mathrm{DE}}$, and on the non-drive end, $C_{\mathrm{b}, \mathrm{NDE}}$. Then, the BVR is given by

$$
\mathrm{BVR}=\frac{v_{\mathrm{b}}}{v_{\mathrm{com}}}=\frac{C_{\mathrm{wr}}}{C_{\mathrm{wr}}+C_{\mathrm{rf}}+C_{\mathrm{b}, \mathrm{DE}}+C_{\mathrm{b}, \mathrm{NDE}}} .
$$

The stator windings in the slots and the rotor surface form $C_{\mathrm{wr}}$. The distance between the two plates of the capacitance is quite long and the width is small, compared with those of $C_{\mathrm{rf}}$. Here, the rather wide teeth, including their tips, face the rotor surface at a very small distance. As per [17], the orders of magnitudes of the three capacitances that form the BVR relate as follows:

$$
\begin{aligned}
C_{\mathrm{wf}} & \approx\left(\frac{1}{10} \ldots \frac{1}{20}\right) C_{\mathrm{rf}}, \\
C_{\mathrm{wf}} & \approx C_{\mathrm{b}} .
\end{aligned}
$$

With the proportions of $C_{\mathrm{rf}}, C_{\mathrm{wr}}$ and $C_{\mathrm{b}}$ given in (2) and (3), the effect of the bearing capacitances $C_{\mathrm{b}}$ on the BVR is small. For example, for $C_{\mathrm{wr}}=C_{\mathrm{b}}=1 / 15 C_{\mathrm{rf}}$, (1) gives $\mathrm{BVR}=5.6 \%$; and, by neglecting the bearing capacitances $C_{\mathrm{b}}, \mathrm{BVR}=6.3 \%$. Based on these numbers, the energy dissipated within the bearing following a breakdown would increase by $(6.3 / 5.6)^{2}=$ $(1.125)^{2}=1.266$. Considering the degree to which the BVR can be determined because of the uncertainty inherent in the estimation of the values of the capacitances $C_{\mathrm{rf}}$ and $C_{\mathrm{wr}}$, this difference is considered acceptable, and the BVR is considered independent of the speed at which the machine operates. Non-zero bearing capacitances always reduce the value of the BVR.

\section{ROTOR-TO-FRAME CAPACITANCE COMPUTATION}

\section{A. Previously Proposed Approach}

The capacitance $C_{\mathrm{rf}}$ is formed between the stator iron and rotor surfaces. As per [5] and [17], the stator and the rotor surfaces may be assumed to form a coaxial air-insulated capacitor, in which the electrodes are separated by $d_{\mathrm{ag}}$. Since the air-gap is small when compared to the rotor diameter, $d_{\mathrm{r}}$, $d_{\mathrm{ag}}<<d_{\mathrm{r}}$, the capacitor can be simplified as an air-insulated plate capacitor with the length of the stator stack, $l_{\mathrm{s}}$, and permittivity of vacuum $\varepsilon_{0}=8.854 \cdot 10^{-12}[\mathrm{~F} / \mathrm{m}]$. In [17], the effect of the stator slot openings is taken into account by the established Carter coefficient $k_{\mathrm{c}}$, which is derived via conformal mapping. With these assumptions, $C_{\mathrm{rf}, \mathrm{cyl}}$ is calculated as

$$
C_{\mathrm{rf}, \mathrm{cyl}}=\varepsilon_{0} \pi \frac{d_{\mathrm{r}} l_{\mathrm{s}}}{k_{\mathrm{c}} d_{\mathrm{ag}}} .
$$

While the cylindrical capacitor approximation and application of $k_{\mathrm{c}}$ are justified, (4) does not explicitly consider the

(C) 2019 IEEE. Personal use of this material is permitted. Permission from IEEE must be obtained for all other uses, in any current or future media, including reprinting/republishing this material for advertising or promotional purposes, creating new collective works, for resale or redistribution to servers or lists, or reuse of any copyrighted component of this work in other works. https://doi.org/10.1109/TIA.2019.2898850 
relation between $w_{\mathrm{s}}$ and $d_{\mathrm{ag}}$ instead, this ratio is considered implicitly within $k_{\mathrm{c}}$.

\section{B. Proposed Normalization Function Based Approach}

In order to explicitly take the slot openings into account, the stator is divided into parallel slot segments (Fig. 2). Each slot forms a capacitance, and all these capacitances are then connected in parallel. To this aim, the stator tooth width is expressed in electric degrees

$$
w_{\mathrm{s}}=\pi \frac{D_{\mathrm{s}}}{n}-w_{\mathrm{so}},
$$

where $D_{\mathrm{s}}$ and $n$ denote the inner diameter of the stator core and the number of stator slots, respectively. By applying this parallel-plate, instead of the cylindrical capacitor approximation, $C_{\mathrm{rf}}$ can then be written as

$$
C_{\mathrm{rf}, \mathrm{pp}}=\varepsilon_{0} n l_{\mathrm{s}} \frac{w_{\mathrm{s}}}{d_{\mathrm{ag}}} .
$$

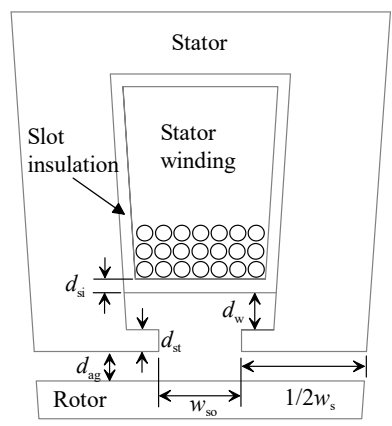

Fig. 2. Schematic of a stator slot segment showing the parameters used in the modelling.

Similar to the case of a micro-strip capacitor over a ground plane (Fig. 3), the capacitor's electrode on the rotor side is wider than that on the stator side: The electric field is homogeneously distributed below the stator teeth and inhomogeneously below the stator slot openings (Fig. 4).

Hence, the slot openings increase the total capacitance when compared with the value of a parallel-plate capacitor with a homogeneously distributed electric field. Thus, the parallel-plate capacitor approximation is amended to better describe this inhomogeneous distribution of the electric field as follows:

The situation resembles the evaluation of distributed capacitances of a micro-strip transmission line typically used for high-frequency signaling on printed circuit boards. An established yet simple method to estimate the transmission line parameters consists of modeling the total capacitance $C$ as sum of the plate capacitances $C_{\mathrm{y}}$ and the so-called fringing capacitance $C_{\mathrm{f}}$ [26], which is the plate ends' contribution to the total capacitance. With this assumption, the normalized rotor-to-frame capacitance, $C_{\mathrm{rf}, \mathrm{N}}$, is expressed analytically,

$$
C_{\mathrm{rf}, \mathrm{N}}=C_{\mathrm{rf}, \mathrm{pp}}\left(1+k_{\mathrm{rf}}\right) \text {, }
$$

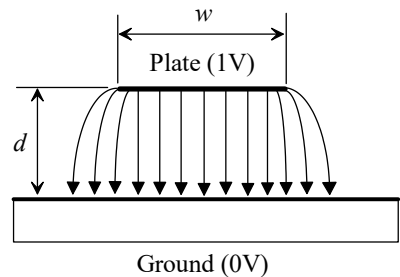

Fig. 3. Micro-strip capacitor over the ground plane and associated electric field; the plate ends increase the total capacitance when compared with an ideal parallel-plate capacitor with a homogenously distributed electric field.

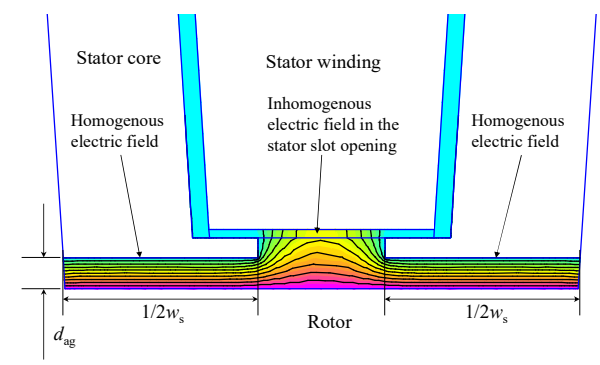

Fig. 4. Electric field between the rotor and the stator frame as determined by the finite element method (electrostatic analysis, realized with Finite Element Methods Magnetics, [25]).

where $k_{\mathrm{rf}}$ is a function of the ratio between $d_{\mathrm{ag}}$ and $w_{\mathrm{s}}$

$$
k_{\mathrm{rf}}=f\left(\frac{d_{\mathrm{ag}}}{w_{\mathrm{s}}}\right),
$$

and is hence dimensionless.

Our claim is that the function $k_{\mathrm{rf}}$ can be estimated, e.g., by an extensive parameter study using numerical analysis, such as the finite element method. Evidently, the range of the parameters studied must be "sufficiently" large, and caution must be used when the results are applied to geometries not covered therein.

\section{STATOR-WINDING-TO-ROTOR CAPACITANCE COMPUTATION}

\section{A. Previously Proposed Approach}

The capacitance $C_{\mathrm{wr}}$ is formed between the stator windings in the slots and the rotor surface. It is much smaller than $C_{\mathrm{rf}}$, see Section II and (2). According to [27] and [28], the stator end winding also contributes to $C_{\mathrm{wr}}$. Especially in small induction machines, such as the off-the-shelf air-cooled $1.5 \mathrm{~kW}$ machine studied in [28], the effect of the end-winding on $C_{\mathrm{wr}}$ was found to be significant. This is explained by the short length of the stator stack when compared to the length of the end-winding as well as the short distance from the endwinding to the rotor end ring. As a result, this coupling and hence its contribution may not necessarily be as substantial in the case of larger machines.

A method to estimate $C_{\mathrm{wr}}$ based on the machine design parameters is presented in [17]. It assumes that each stator slot forms a parallel plate capacitor with the rotor surface, with a

(C) 2019 IEEE. Personal use of this material is permitted. Permission from IEEE must be obtained for all other uses, in any current or future media, including reprinting/republishing this material for advertising or promotional purposes, creating new collective works, for resale or redistribution to servers or lists, or reuse of any copyrighted component of this work in other works. https://doi.org/10.1109/TIA.2019.2898850 
plate width of $w_{\text {so }}$ and length $l_{\mathrm{s}}$ (Fig. 2). The distance between the plates comprises $d_{\mathrm{ag}}$, the stator tooth tip thickness $d_{\mathrm{st}}$, the distance from the stator-slot to the winding $d_{\mathrm{w}}$, and the slot insulation thickness $d_{\text {si }}$ (Fig. 2). Thus, a series connection of capacitors is formed with different relative permittivities $\varepsilon_{\text {r }}$. $C_{\text {wr,pp }}$ and is then given by

$$
C_{\mathrm{wr}, \mathrm{pp}}=\varepsilon_{0} n l_{\mathrm{s}} \frac{w_{\mathrm{so}}}{d_{\mathrm{ag}}+\frac{d_{\mathrm{st}}}{\varepsilon_{\mathrm{r}, \mathrm{st}}}+\frac{d_{w}}{\varepsilon_{\mathrm{r}, \mathrm{w}}}+\frac{d_{\mathrm{si}}}{\varepsilon_{\mathrm{r}, \mathrm{si}}}} .
$$

The proposed pure plate capacitor approach may overestimate the capacitance [28]. This is again explained by the inhomogeneous electric field distribution between the stator winding and the rotor (Fig. 5).

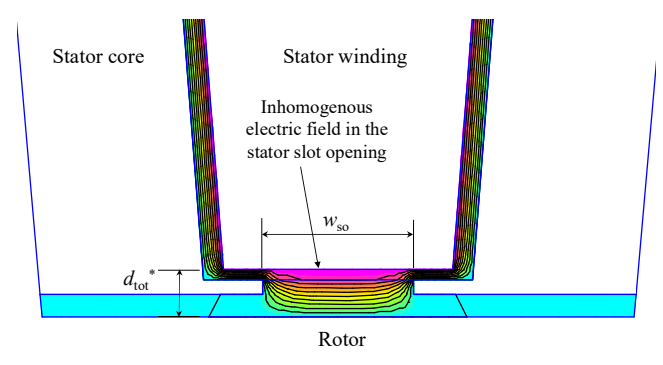

Fig. 5. Inhomogeneous electric field distribution between the stator slot opening and the rotor as determined by the finite element method (electrostatic analysis, realized with Finite Element Methods Magnetics, [25]).

\section{B. Proposed Normalization Function Based Approach}

The authors of [29] remark that the electric field distribution in the stator slot opening is inhomogeneous due to the complex geometrical design. Thus, use of an FEM model for the calculation of the capacitance, as a part of the machine design, is proposed.

The traditional parallel-plate capacitor approach has a low number of parameters that are readily available as part of the machine design process and provide a fairly explicit relationship between these and the computed capacitance. The authors of [30] proposed considering the inhomogeneous field of a parallel-plate capacitor with a long distance $d$ between the electrodes compared to their width $w$ by normalizing the parallel-plate approximation by an adjustment coefficient $k_{\mathrm{wr}}$. This coefficient is a function of the aspect ratio $b$,

$$
b=\frac{d}{w}
$$

and is derived from numerical computations using the boundary element method. This paper proposes using a similar dimensionless adjustment function $k_{\mathrm{wr}}$ to calculate the normalized stator-winding-to-rotor capacitance $C_{\mathrm{wr}, \mathrm{N}}$ based on the parallel-plate capacitor approximation of (9). It is defined as

$$
\begin{aligned}
& C_{\mathrm{wr}, \mathrm{N}}=k_{\mathrm{wr}} C_{\mathrm{wr}, \mathrm{pp}}, \text { with } \\
& k_{\mathrm{wr}}=f\left(\frac{d_{\mathrm{tot}}}{w_{\mathrm{so}}}\right) \text { and }
\end{aligned}
$$

$$
d_{\mathrm{tot}}=d_{\mathrm{ag}}+\frac{d_{\mathrm{st}}}{\varepsilon_{\mathrm{r}, \mathrm{st}}}+\frac{d_{w}}{\varepsilon_{\mathrm{r}, \mathrm{w}}}+\frac{d_{\mathrm{si}}}{\varepsilon_{\mathrm{r}, \mathrm{si}}},
$$

where $d_{\text {tot }}$ denotes the effective distance between the electrodes in the parallel-plate capacitor. Once again, the claim made in this paper is that the function $k_{\mathrm{wr}}$ can be estimated, e.g., by an extensive parameter study using numerical analysis.

\section{DETERMINATION OF THE NORMALIZATION FUNCTIONS}

Simplified electrostatic FEM models of the stator slot segments for two general purpose three-phase, four-pole, delta connected induction machines were developed. The first, M15kW, was a $15 \mathrm{~kW}$ with a shaft height of $160 \mathrm{~mm}$, and the second, M37kW, a $37 \mathrm{~kW}$ machine with a shaft height of $225 \mathrm{~mm}$. These machines were also selected for the experimental investigations. They are further described below in Section VI, where Table I also shows the parameters of the machines. These FEM models comprise the original slot segment and the rotor surface and are considered as reference models (Fig. 5).

\section{A. Numerical Computation of the Normalized Capacitances $C_{\mathrm{wr}, \mathrm{N}}$ and $C_{\mathrm{rf}, \mathrm{N}}$}

The normalized capacitances $C_{\mathrm{wr}, \mathrm{N}}$ and $C_{\mathrm{rf}, \mathrm{N}}$ are determined via FEM models as follows: First, a potential of $1 \mathrm{~V}$ is connected to the stator winding, while both the stator and the rotor are connected to a potential of $0 \mathrm{~V}$. The resulting total charge of $Q_{1}$ is retrieved and the resulting capacitance $C_{1}$ calculated as follows

$$
C_{1}=\frac{Q_{1}}{1 \mathrm{~V}}
$$

Next, the rotor is removed from the model, and the same procedure to calculate the total capacitance is repeated to retrieve $C_{2}$. Finally, $C_{\mathrm{wr}, \mathrm{N}}$ is calculated by

$$
C_{\mathrm{wr}, \mathrm{N}}=n\left(C_{1}-C_{2}\right) \text {. }
$$

Correspondingly, $C_{\mathrm{rf}, \mathrm{N}}$ is determined as follows: The rotor is connected to a potential of $1 \mathrm{~V}$ and the stator to $0 \mathrm{~V}$. This time, the stator winding is removed from the FEM-model. Again the total charge and the resulting capacitance $C_{3}$ are computed and $C_{\mathrm{rf}, \mathrm{N}}$ is determined as

$$
C_{\mathrm{rf}, \mathrm{N}}=n C_{3} .
$$

Next, extensive parameter studies on $d_{\mathrm{ag}}, d_{\mathrm{w}}$, and $w_{\mathrm{so}}$ were conducted, using numerical analysis. The stator tooth tip thickness $d_{\text {st }}$ was kept constant, since preliminary FEM investigations had shown that varying this parameter has almost the same effect on $C_{\mathrm{wr}}$ as simply adjusting the distance $d_{\mathrm{w}}$.

\section{B. Derivation of the Normalization Functions $k_{r f}$ and $k_{w r}$}

For all the different scenarios, the values of $C_{\mathrm{rf}}$ and $C_{\mathrm{wr}}$ were calculated analytically from (6) and (9), respectively. The relationship between $C_{\mathrm{rf}, \mathrm{N}}$ and $C_{\mathrm{rf}, \mathrm{pp}}$ as a function of

(C) 2019 IEEE. Personal use of this material is permitted. Permission from IEEE must be obtained for all other uses, in any current or future media, including reprinting/republishing this material for advertising or promotional purposes, creating new collective works, for resale or redistribution to servers or lists, or reuse of any copyrighted component of this work in other works. https://doi.org/10.1109/TIA.2019.2898850 
$d_{\mathrm{ag}} / w_{\mathrm{s}}$, quantified by the function $k_{\mathrm{rf}}$ according to (7), is illustrated in Fig. 6, indicating a linear relationship. By employing the least mean squares (LMS) algorithm for a linear curve, an empirical expression for the correction coefficient $k_{\mathrm{rf}}$ is derived,

$$
k_{\mathrm{rf}}=2.3 \frac{d_{\mathrm{ag}}}{w_{s}} .
$$

The correlation of this linear fitting is $R^{2}=0.87$.

The corresponding results for the ratio $C_{\mathrm{wr}, \mathrm{N}} / C_{\mathrm{wr}, \mathrm{pp}}$ as a function of $d_{\mathrm{tot}} / w_{\mathrm{so}}$, i.e., the adjustment function $k_{\mathrm{wr}}$ according to (11), is shown in Fig. 7, indicating a relatively exponential relationship.

Applying LMS again, the following expression for the correction coefficient $k_{\mathrm{wr}}$ is derived

$$
k_{\mathrm{wr}}=1.194 \mathrm{e}^{-2.81 d_{\mathrm{tot}} / w_{\mathrm{so}}} .
$$

Here, the correlation of fitting is $R^{2}=0.99$.

In both cases, the coefficients are derived from the data points computed for both machines. The results shown in Fig. 6 and 7 indicate that the same dimensionless normalization functions seem to be applicable, at least, for both of the investigated induction machines $\mathrm{M} 15 \mathrm{~kW}$ and $\mathrm{M} 37 \mathrm{~kW}$ and their stator slot segment design variants. The high degree of fitting indicates that the method can also be applied to other machines without the need of further intensive parameter studies beforehand. Evidently, further research on additional machines will increase the insight into the generic nature of the normalization functions (8) and (12) as well as the correction coefficients presented in (17) and (18).

When comparing Figs. 6 and $7, k_{\mathrm{wr}}$ shows a higher degree of fitting than $k_{\mathrm{rf}}$. This is explained by the wide open slots of the example case machine used for the numerical calculations, whereby the fringing capacitance between the stator and rotor surfaces is more affected by the slot opening than that which is between the stator winding and the rotor surface. We assume with almost open stator slots (such as with the example case machine) the effect of the stator slot sidewalls on $C_{\mathrm{rf}}$ could potentially increase. Still, because of (7), any error in $k_{\mathrm{rf}}$ only translates as a smaller error into the value of $C_{\mathrm{rf}}$.

\section{EXPERIMENTAL INVESTIGATIONS}

\section{A. Example Case Machines $M 15 \mathrm{~kW}$ and $M 37 \mathrm{~kW}$}

For both example case machines, M15kW and M37kW, first, the total rotor-to-stator-frame capacitances were measured with a Keysight U1733C handheld LCR meter using an excitation frequency of $1 \mathrm{kHz}$. Next, both machines were driven with a frequency converter (operating at the default switching frequency of $4 \mathrm{kHz}$ ) at nominal speed, while the voltages across the bearings and the common mode voltage at the stator terminals were measured. For these, a Rohde \& Schwartz RTO 1014 oscilloscope, along with Rohde \& Schwartz differential voltage probes RT-ZD01 and an arti-

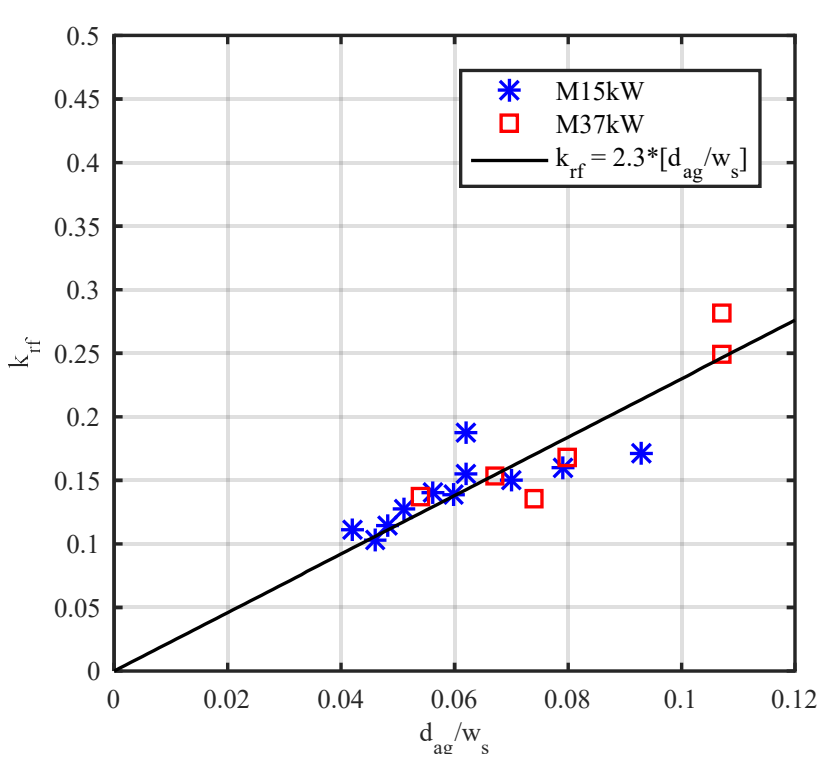

Fig. 6. Numerically determined normalization coefficients $k_{\mathrm{rf}}$ for the parallelplate capacitor approximation as a function of $d_{\mathrm{ag}} / w_{\mathrm{s}}$ for different ratios $d_{\mathrm{ag}} / w_{\mathrm{s}}$ of the two example case machines M15kW and M37kW.

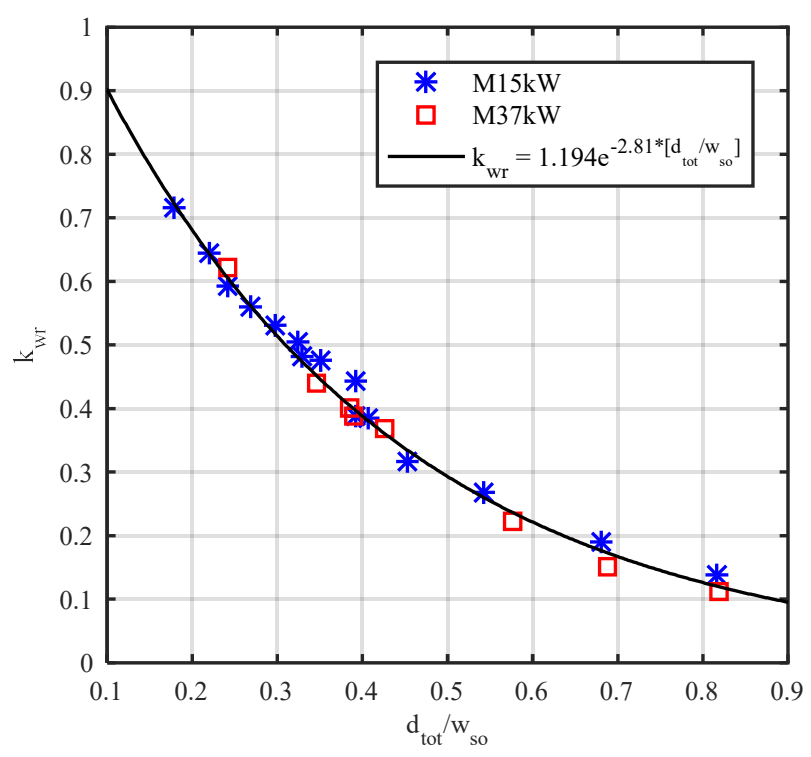

Fig. 7. Numerically determined adjustment coefficients $k_{\mathrm{wr}}$ for the parallelplate capacitor approximation as a function of $d_{\text {tot }} / w_{\text {so }}$ for different ratios $d_{\text {tot }} / w_{\text {so }}$ of the two example case machines M $15 \mathrm{~kW}$ and M $37 \mathrm{~kW}$.

ficial star point made of three $1 \mathrm{M} \Omega$ resistors were used.

The BVRs were determined from the measured common mode and bearing voltages (Fig. 8). Furthermore, the experimentally determined stator-winding-to-frame capacitances $C_{\mathrm{wr} \text {,exp }}$ were computed from (1), along with the measured total rotor-to-frame capacitances $C_{\mathrm{rf} \text { exp }}$ and estimates of $C_{\mathrm{b}}$. The machine parameters as well as the different measured and estimated quantities are shown in Table I, in the two far right columns. Considering the geometries of the machine winding overhangs, the capacitance between the winding overhangs

(C) 2019 IEEE. Personal use of this material is permitted. Permission from IEEE must be obtained for all other uses, in any current or future media, including reprinting/republishing this material for advertising or promotional purposes, creating new collective works, for resale or redistribution to servers or lists, or reuse of any copyrighted component of this work in other works. https://doi.org/10.1109/TIA.2019.2898850 

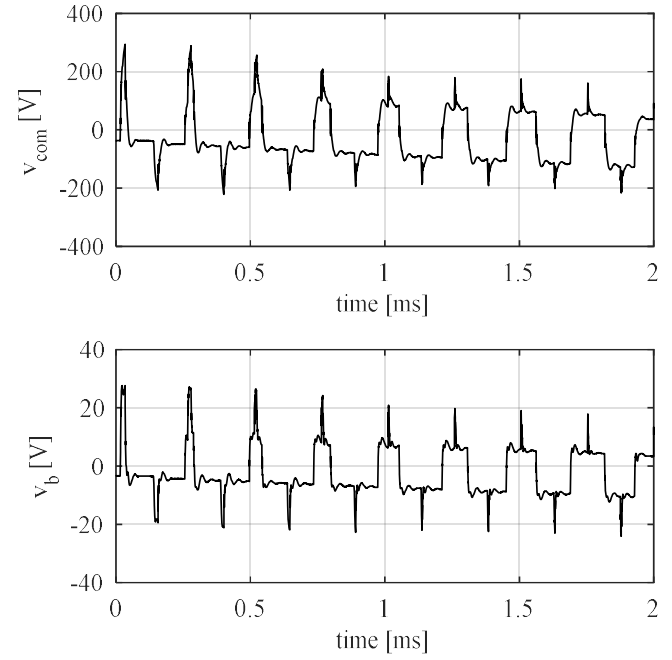

Fig. 8. M15kW fed with $50 \mathrm{~Hz}$ supply frequency with a two-level frequency converter. Top: common-mode voltage measured at the stator terminals. Bottom: measured voltage across the bearing.

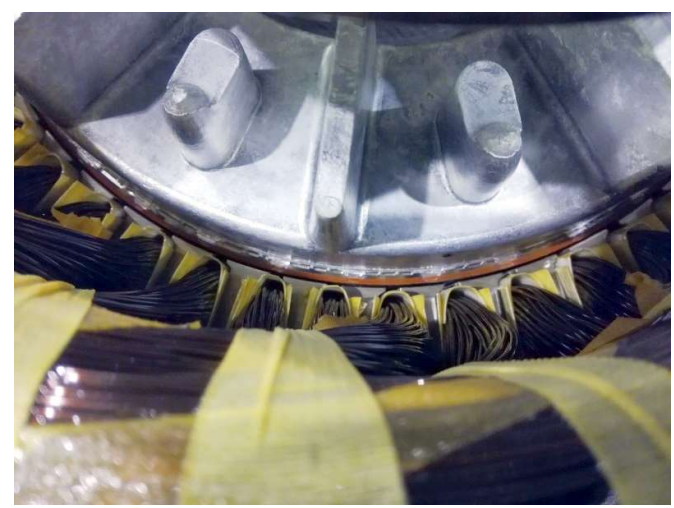

Fig. 9. Non-drive-end of example case machine M37kW, the winding overhang increases the total winding-to-rotor capacitance, here estimated to be $10-20 \mathrm{pF}$

and the rotor is approximated at (10-20) $\mathrm{pF}$ for both machines, e.g., M37kW shown in Fig. 9. (For the computations, a mean value of $15 \mathrm{pF}$ is used.) This capacitance is between $5 \%$ and $20 \%$ of their total stator-winding-to-rotor capacitances, which is well in line with the values presented in [27] and [28].

For the investigated machines and based on machine design data, the proposed normalization method gives slightly lower values than those experimentally determined, both for $C_{\mathrm{wr} \text {,exp }}$ and $C_{\text {rf,exp }}($ Table I). For $\mathrm{M} 15 \mathrm{~kW}$, the estimated capacitance $C_{\mathrm{wr}, \mathrm{N}}+C_{\mathrm{wr}, \text { end }}(172 \mathrm{pF}+15 \mathrm{pF}=187 \mathrm{pF})$ is $6.5 \%$ smaller than the measured capacitance $(200 \mathrm{pF})$, the estimated capacitance $C_{\mathrm{rf}, \mathrm{N}}$ is $10 \%$ smaller that the measured capacitance $(1890 \mathrm{pF}$ versus $2150 \mathrm{pF})$. For $\mathrm{M} 37 \mathrm{~kW}$, the differences are $-19 \%$ $(78 \mathrm{pF}+15 \mathrm{pF}=93 \mathrm{pF}$ versus $115 \mathrm{pF})$ and $-9 \%(1280 \mathrm{pF}$ versus $1400 \mathrm{pF}$ ), respectively. More research may identify the contributions to the capacitance not yet considered, thereby increasing the accuracy of the prediction. However, the degree to which the capacitances are predicted is acceptable, and it is well in line with other approaches of similar complexity.

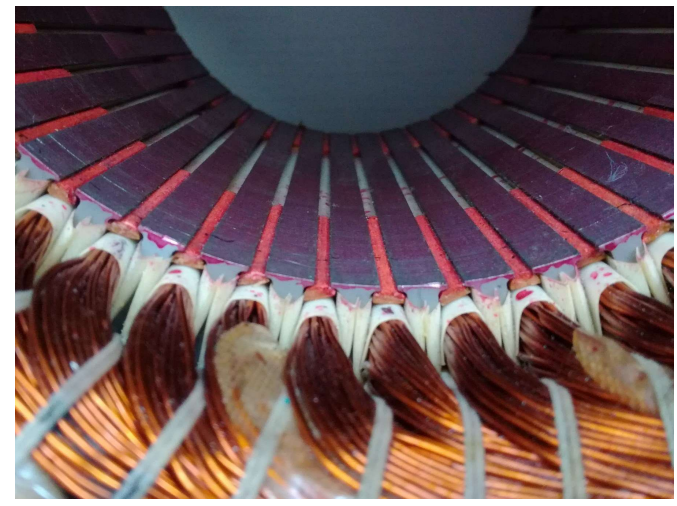

Fig. 10. Non-drive-end of example case machine $\mathrm{M} 15 \mathrm{kWb}$; the stator slot wedges cover only $50 \%$ of the slot length.

Furthermore, it is readily applicable, including for the purpose of straightforward parameter studies.

The BVRs determined by the proposed normalization method differ by $2 \%$ and by $-19 \%$ from the experimentally determined values, for $\mathrm{M} 15 \mathrm{~kW}$ and for $\mathrm{M} 37 \mathrm{~kW}$, respectively. The figures provided in Table I also show that the values of the BVR determined by the proposed methods differ less from the experimental values than those determined by the conventional method.

\section{B. Further Example Case Machines M15kWa and M15kWb}

To further study the applicability of the proposed statorwinding-to-rotor and rotor-to-frame capacitance estimation methods, two additional induction machines, motors $\mathrm{M} 15 \mathrm{kWa}$ and $\mathrm{M} 15 \mathrm{kWb}$, were experimentally investigated. $\mathrm{M} 15 \mathrm{kWa}$ was identical to $\mathrm{M} 15 \mathrm{~kW}$, with one significant difference, namely, the machine stator insulation was strengthened by additional slot wedges mounted directly inside the stator slot openings. This increased the distance between the stator and the rotor surface. The 4-pole machine $\mathrm{M} 15 \mathrm{kWb}$ was from a different manufacturer than machines $\mathrm{M} 15 \mathrm{~kW}$ and $\mathrm{M} 15 \mathrm{kWa}$. It had 48 stator slots with approximately only $50 \%$ of the length of the slot covered with the slot wedge, while the rest of the slot length was not covered at all (Fig. 10). Motor M15kWb had a shaft height of $160 \mathrm{~mm}$, a stator stack length of $195 \mathrm{~mm}$, and a stator inner diameter of $161 \mathrm{~mm}$. The airgap length was estimated to be $0.35 \mathrm{~mm}$. Motor M15kWb was equipped with conventional $6309 \mathrm{C} 3$ bearings at the ends. However, the outer rings of the bearings were electrically insulated from the motor end plates with polyethylene sleeves. Once more, as with the example case machines $\mathrm{M} 15 \mathrm{~kW}$ and M15kWa, considering the geometries of the machine winding overhangs, the capacitance between the winding overhangs and the rotor is again approximated to be $(10-20) \mathrm{pF}$ for both machines. Likewise, the machine parameters, as well as the different measured and estimated quantities are shown in Table I (second and third column).

In most cases, the proposed normalization method gives slightly lower values than those experimentally determined (Table I). For M15kWa, the estimated capacitance $C_{\mathrm{wr}, \mathrm{N}}+$

(C) 2019 IEEE. Personal use of this material is permitted. Permission from IEEE must be obtained for all other uses, in any current or future media, including reprinting/republishing this material for advertising or promotional purposes, creating new collective works, for resale or redistribution to servers or lists, or reuse of any copyrighted component of this work in other works. https://doi.org/10.1109/TIA.2019.2898850 
TABLE I

DESIGN DATA, MEASURED, ESTIMATED AND CALCULATED PARAMETERS OF THE EXAMPLE CASE MACHINES

\begin{tabular}{|c|c|c|c|c|}
\hline & M15kWa & M15kWb & M15kW & $\mathbf{M 3 7 k W}$ \\
\hline \multicolumn{5}{|l|}{ Design parameters } \\
\hline Power $[\mathrm{kW}]$ & 15 & 15 & 15 & 37 \\
\hline Pole number & 4 & 4 & 4 & 4 \\
\hline Shaft height $[\mathrm{mm}]$ & 160 & 160 & 160 & 225 \\
\hline Bearing types (DE/NDE) & $\begin{array}{c}\text { 6309/6208 C3 } \\
\text { hybrid }\end{array}$ & $\begin{array}{c}6309 \mathrm{C} 3 \\
\text { insulated with } \\
\text { PE sleeves }\end{array}$ & $\begin{array}{c}\text { 6309/6208 C3 } \\
\text { hybrid }\end{array}$ & $6313 / 6213 \mathrm{C} 3$ \\
\hline Number of stator slots $n$ & 36 & 48 & 36 & 48 \\
\hline Air gap $d_{\mathrm{ag}}[\mathrm{mm}]$ & 0.55 & 0.35 & 0.55 & 0.93 \\
\hline Stator inner diameter $D_{\mathrm{s}}[\mathrm{mm}]$ & 165 & 161 & 165 & 235 \\
\hline Stator core length $l_{\mathrm{s}}[\mathrm{mm}]$ & 270 & 195 & 270 & 205 \\
\hline \multicolumn{5}{|l|}{ Measured capacitances and BVRs } \\
\hline Total rotor-to-frame capacitance $C_{\mathrm{rf}, \text { tot,exp }}=C_{\mathrm{rf}}+C_{\mathrm{b}, \mathrm{DE}}+C_{\mathrm{b}, \mathrm{NDE}}[\mathrm{pF}]$ & 2200 & 2300 & 2200 & 3600 \\
\hline Bearing capacitances $C_{\mathrm{b}, \mathrm{DE}}+C_{\mathrm{b}, \mathrm{NDE}}[\mathrm{pF}]$ (estimated) & 100 & 200 & 100 & 2200 \\
\hline Rotor-to-frame capacitance $C_{\mathrm{rf}, \exp }[\mathrm{pF}]$ & 2100 & 2100 & 2150 & 1400 \\
\hline Bearing-voltage-ratio BVR [\%] & 3.3 & 2.9 & 8.4 & 3.1 \\
\hline Stator-winding-to-rotor capacitance $C_{\mathrm{wr}, \exp }=\mathrm{BVR} \cdot C_{\mathrm{rf}, \text { tot }}(1-\mathrm{BVR})[\mathrm{pF}]$ & 75 & 69 & 200 & 115 \\
\hline \multicolumn{5}{|c|}{ Estimated rotor-to-frame and stator-winding-to-rotor capacitances according to $(4),(6)$ and (9) ${ }^{\dagger}$} \\
\hline Carter coefficient $k_{\mathrm{c}}$ & 1.04 & 1.06 & 1.04 & 1.03 \\
\hline $\mathrm{C}_{\mathrm{rf}, \mathrm{cyl}}[\mathrm{pF}]$ & 2149 & 2335 & 2149 & 1388 \\
\hline$C_{\mathrm{rf}, \mathrm{pp}}[\mathrm{pF}]$ & 1680 & 1780 & 1680 & 1090 \\
\hline$C_{\mathrm{wr}, \mathrm{pp}}[\mathrm{pF}]$ & 181 & 173 & 319 & 205 \\
\hline BVR [\%], according to (1) based on $C_{\mathrm{rf}, \mathrm{cyl}}$ and $C_{\mathrm{wr}, \mathrm{pp}}$ & 7.4 & 6.4 & 12.0 & 5.4 \\
\hline BVR [\%], according to (1) based on $C_{\mathrm{rf}, \mathrm{pp}}$ and $C_{\mathrm{wr}, \mathrm{pp}}$ & 9.2 & 8.0 & 15.6 & 5.9 \\
\hline \multicolumn{5}{|c|}{$C_{\mathrm{rf}}$ and $C_{\mathrm{wr}}$ adjusted with the correction coefficients $k_{\mathrm{rf}}$ and $k_{\mathrm{wr}}$ according to (7) and (11), and $k_{\mathrm{rf}}$ and $k_{\mathrm{wr}}$ as per Fig. 6 and $7^{\dagger}$} \\
\hline$C_{\mathrm{rf}, \mathrm{N}}[\mathrm{pF}]$ & 1890 & 1980 & 1890 & 1280 \\
\hline$C_{\mathrm{wr}, \mathrm{N}}[\mathrm{pF}]$ & 57 & 54 & 172 & 78 \\
\hline$C_{\mathrm{wr}, \text { end }}[\mathrm{pF}]$ (estimated) & $10-20$ & $10-20$ & $10-20$ & $10-20$ \\
\hline$C_{\mathrm{rf}, \mathrm{N}}+C_{\mathrm{wr}, \text { end }}[\mathrm{pF}]$ & 72 & 69 & 187 & 93 \\
\hline BVR [\%], according to (1) & 3.5 & 3.1 & 8.6 & 2.5 \\
\hline \multicolumn{5}{|l|}{ Differences between the computed and the measured values } \\
\hline$C_{\mathrm{rf}}$ & $-10 \%$ & $-6 \%$ & $-10 \%$ & $-9 \%$ \\
\hline$C_{\mathrm{wr}}$ & $-4 \%$ & $0 \%$ & $-6.5 \%$ & $-19 \%$ \\
\hline BVR & $6 \%$ & $7 \%$ & $2 \%$ & $-19 \%$ \\
\hline
\end{tabular}

$\dagger$ Relative permittivity of the stator slot insulation and stator wedge materials assumed as 3 .

$C_{\mathrm{wr}, \text { end }}(57 \mathrm{pF}+15 \mathrm{pF}=72 \mathrm{pF})$ is $4 \%$ smaller than the measured one $(75 \mathrm{pF})$, and the estimated capacitance $C_{\mathrm{rf}, \mathrm{N}}$ is $10 \%$ smaller that the measured one (1890 $\mathrm{pF}$ versus $2100 \mathrm{pF})$. For $\mathrm{M} 15 \mathrm{kWb}$, the differences are (approximately) $0 \%(54 \mathrm{pF}$ $+15 \mathrm{pF}=69 \mathrm{pF}$ versus $69 \mathrm{pF})$ and $-6 \%(1980 \mathrm{pF}$ versus $2100 \mathrm{pF})$, respectively.

The BVRs estimated with the proposed method give results that are well in line with those measured. However, the pure plate-capacitor approach overestimates the BVR, as well as the conventional approaches do, even when the end-winding capacitance is not taken into account.

Considering all four machines investigated, the errors between the computed and measured capacitances vary between zero and close to $20 \%$. This mirrors the influence of parameter uncertainties, such as, notably, the statistical distribution of the windings in the slot and the uncertainty of the estimation of the capacitance between the stator winding overhang and the rotor. Actually, if $C_{\mathrm{wr} \text {,end }}$ of machine $\mathrm{M} 37 \mathrm{~kW}$ is estimated to $25 \mathrm{pF}$, the error of $C_{\mathrm{wr}}$ is only $-10 \%$.

\section{EXPLOITATION: PARAMETER SENSITIVITY ANALYSIS}

\section{A. Simplified estimation of BVR}

To study the influence of the stator slot parameter on the BVR, the expression of the BVR (1) is approximated by

(C) 2019 IEEE. Personal use of this material is permitted. Permission from IEEE must be obtained for all other uses, in any current or future media, including reprinting/republishing this material for advertising or promotional purposes, creating new collective works, for resale or redistribution to servers or lists, or reuse of any copyrighted component of this work in other works. 
considering the orders of magnitude of the parameters in (2) and (3),

$$
\mathrm{BVR} \approx \frac{C_{\mathrm{wr}}}{C_{\mathrm{rf}}} .
$$

Applying (6), (9) and (13) as well as (17) and (18) results in

$$
\mathrm{BVR} \approx \frac{w_{\mathrm{so}} d_{a g}}{w_{s} d_{\mathrm{tot}}} \cdot \frac{1.194 e^{-2.81 d_{\mathrm{ot}} / w_{\mathrm{so}}}}{1+2.3 \frac{d_{\mathrm{ag}}}{w_{\mathrm{s}}}}
$$

This expression is further simplified by approximating $1+2.3 d_{\mathrm{ag}} / w_{\mathrm{s}} \approx 1.194$, as per Fig. 6 ,

$$
\mathrm{BVR} \approx \frac{w_{\mathrm{so}} d_{a g}}{w_{s} d_{\mathrm{tot}}} \cdot e^{-2.81^{d_{\mathrm{tot}}} / w_{\mathrm{so}}} .
$$

As per (21), the BVR mainly depends on two terms: The first, $w_{\mathrm{so}} / w_{\mathrm{s}} \cdot d_{\mathrm{ag}} / d_{\mathrm{tot}}$ describes the ratio of the stator windingto-rotor and the rotor-to-frame capacitances when considered in a simplified way as parallel plate capacitors. The second, $e^{-2.81 \text { dtot } w \text { so }}$ normalizes the error introduced by this simplification.

The BVR, as per (21), will be slightly overestimated, because the bearing capacitances have been eliminated. On the other hand, neglecting the stator end winding capacitance will cause a slight underestimation. Since the proposed approach aims at identifying trends and sensitivities, the influences of these two simplifications on the value of the BVR are assumed to compensate each other approximately.

\section{B. Effect of Stator Slot Parameters on the BVR}

According to (21), the BVR can be most effectively affected by adjusting both $d_{\text {tot }}$ and $w_{\text {so. }}$. As per (13), $d_{\text {tot }}$ can be most effectively modified by adjusting the distance between the stator winding and the stator inner surface, i.e., the distances $d_{\mathrm{st}}, d_{\mathrm{w}}$, and $d_{\mathrm{si}}$, as per (9), and, though less effectively, because $\varepsilon_{\text {rair }}=1$, by $d_{\text {ag }}$. However, the latter is typically fully determined by the electromechanical design, often using experimentally defined equations (e.g., [31] and [32].) This also limits the adjustment of $w_{\mathrm{s}}$. Commonly, $w_{\mathrm{so}}$ is chosen small so as to reduce noise; only a minimum is required to insert the windings into the slot. In practical design cases, $d_{\text {tot }}$ may possibly only be adjusted by the modification of the distance of the stator winding bottom from the stator surface. This will, in turn, reduce the fill factor of the slot. Another possibility to further decrease the BVR would be to add an electromagnetic shield into the stator slot opening (e.g., [33]-[35]).

The motor capacitance estimation method proposed in this paper was applied to determine BVR surfaces for the two example case machines, $\mathrm{M} 15 \mathrm{~kW}$ and $\mathrm{M} 37 \mathrm{~kW}$, as a function of $w_{\mathrm{so}}$ and of the distance of the stator windings from the rotor surface, $\left(d_{\mathrm{w}}+d_{\mathrm{st}}\right)$. These parameters were adjusted by $\pm 25 \%$ around the design point. The results are shown in Fig. 11 and 12. The sensitivity is much stronger in the case of the smaller machine, than with the larger machine. Such relationships could be made available during the design process. They

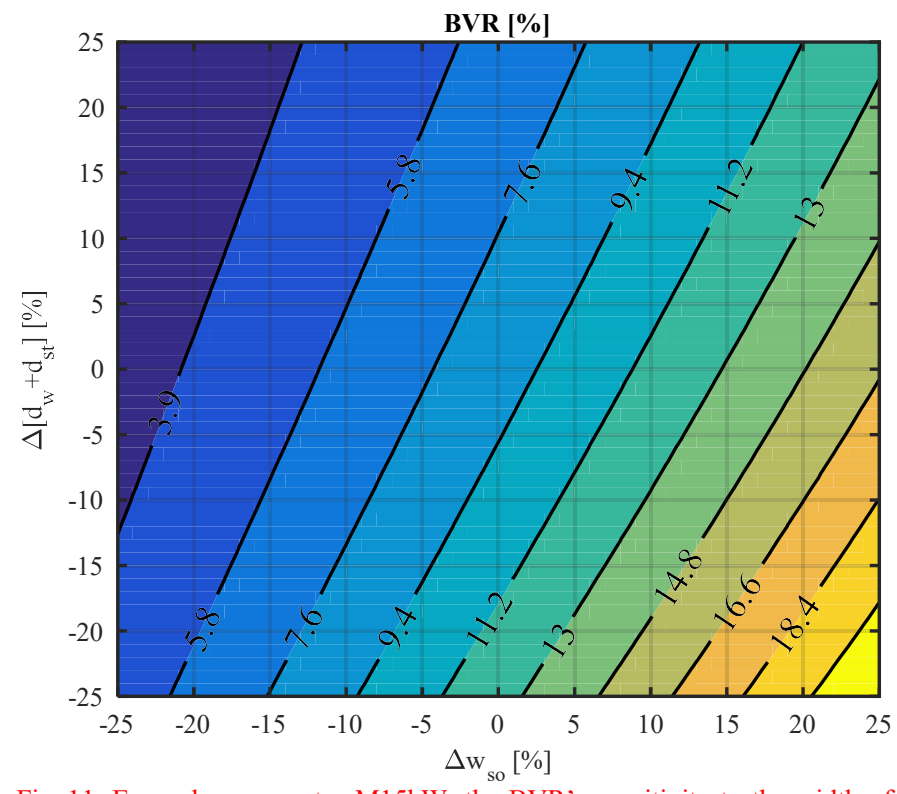

Fig. 11. Example case motor M15kW: the BVR's sensitivity to the width of the slot opening, $w_{\text {so }}$, and the stator windings' distance from the rotor surface, $\left(d_{\mathrm{w}}+d_{\mathrm{st}}\right)$

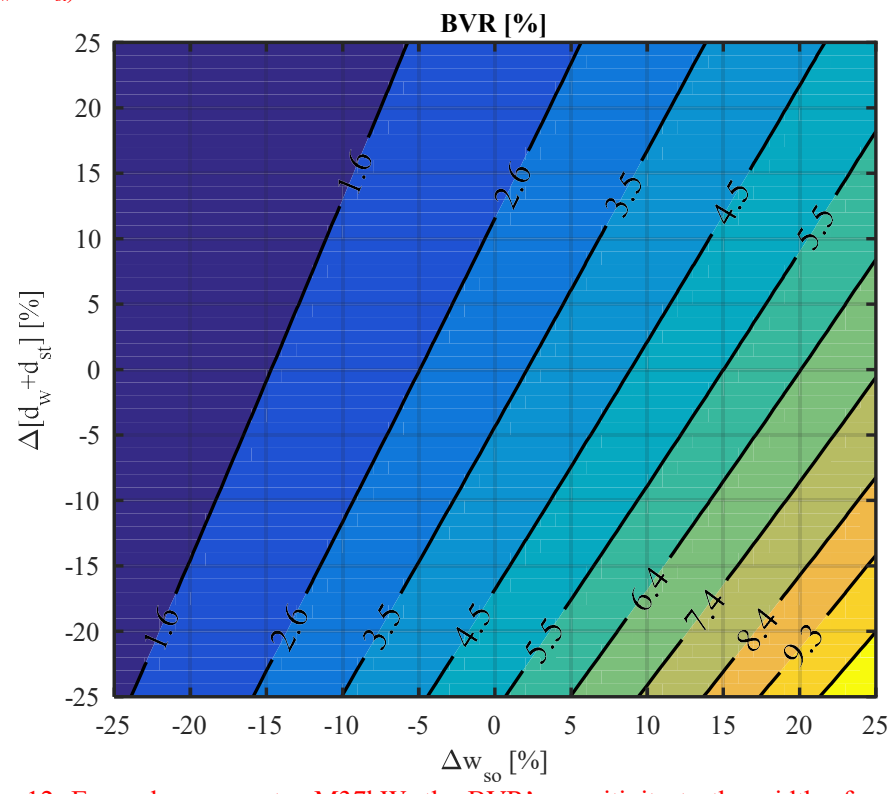

Fig. 12. Example case motor M37kW: the BVR's sensitivity to the width of the slot opening, $w_{\mathrm{so}}$, and the stator windings' distance from the rotor surface, $\left(d_{\mathrm{w}}+d_{\mathrm{st}}\right)$.

illustrate well the possibilities of reducing the BVR at this stage, as part of a design trade-off, and other system parameters.

\section{Effect of Stator Slot Parameters on the Energy Stored in Between the Rotor and the Stator}

When an EDM discharge occurs, the energy stored in the rotor-circuit, $E_{\mathrm{rf}}$, directly influences the heating, melting and vaporization of the bearing races' steel and balls as well as the degrading of the bearing grease,

$$
E_{\mathrm{rf}}=\frac{1}{2} C_{\mathrm{rf}} v_{\mathrm{b}}^{2} .
$$

(C) 2019 IEEE. Personal use of this material is permitted. Permission from IEEE must be obtained for all other uses, in any current or future media, including reprinting/republishing this material for advertising or promotional purposes, creating new collective works, for resale or redistribution to servers or lists, or reuse of any copyrighted component of this work in other works. https://doi.org/10.1109/TIA.2019.2898850 
Similar to the approach used in the previous section, the sensitivities of the energy stored in the rotor capacitances as a function of $w_{\text {so }}$ and of $\left(d_{\mathrm{w}}+d_{\mathrm{st}}\right)$ was determined, see Fig. 13

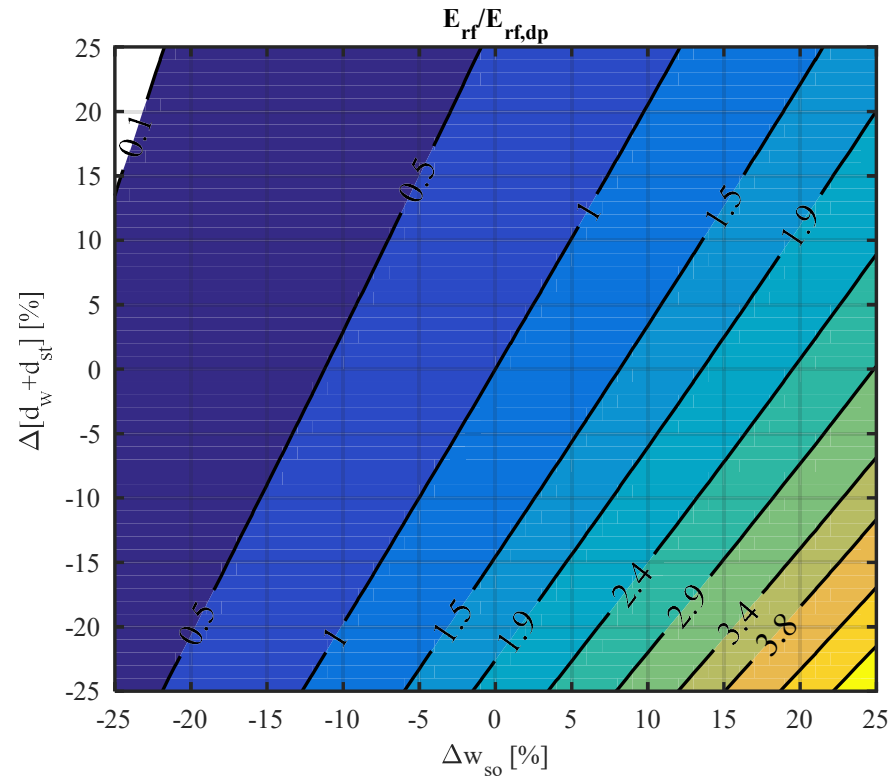

Fig. 13. Example case motor M15kW: sensitivity of the energy stored in the rotor-circuit, $E_{\mathrm{r} f}$, to the width of the slot opening, $w_{\mathrm{so}}$, and of the distance of the stator windings from the rotor surface, $\left(d_{\mathrm{w}}+d_{\mathrm{st}}\right)$.

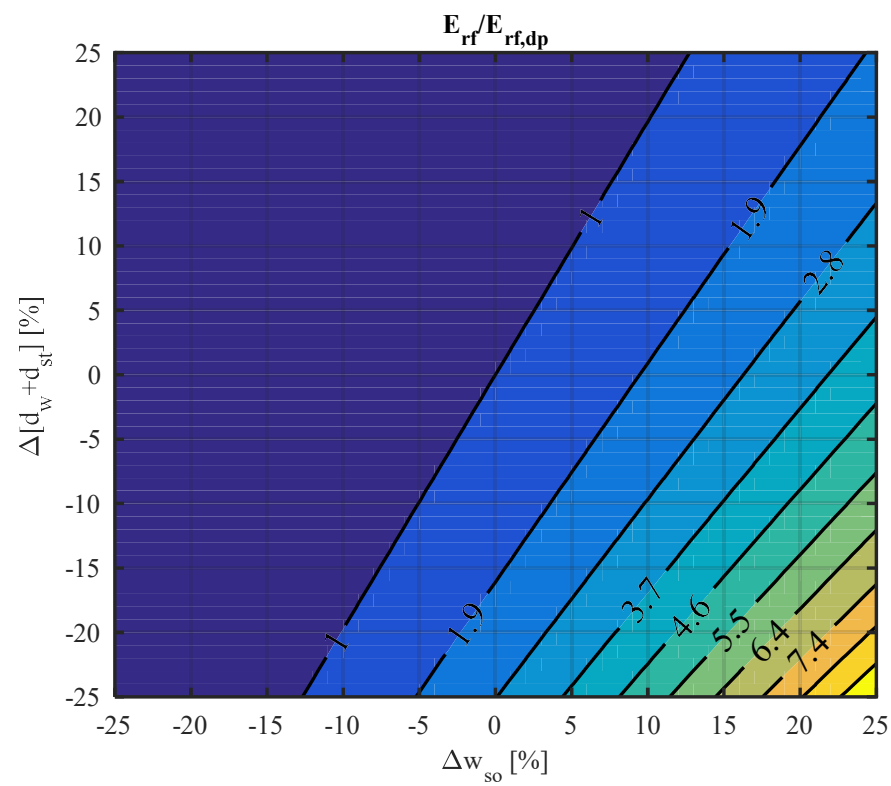

Fig. 14. Example case motor M37kW: sensitivity of the energy stored in the rotor-circuit, $E_{\mathrm{rf}}$, to the width of the slot opening, $w_{\mathrm{so}}$, and of the distance of the stator windings from the rotor surface, $\left(d_{\mathrm{w}}+d_{\mathrm{st}}\right)$.

and 14: A $25 \%$ increase in $w_{\text {so }}$ and decrease of $d_{\mathrm{w}}+d_{\mathrm{st}}$ can increase $E_{\mathrm{rf}}$ by more than a factor of seven .

\section{CONCLUSIONS}

Modeling of parameters that significantly influence the occurrence of inverter-induced bearing currents may not only be used for the analysis of existing systems and the selection of suitable mitigation techniques, but also during the different design stages. This reduces the likeliness of bearing damage as part of the trade-off of the overall choices to be made. To this aim, modeling approaches are required that allow studying the sensitivity of the bearing-current related parameter of interest towards certain design parameters.

This paper presented such an approach for the capacitances formed by the stator winding and the rotor and by the rotor and the frame for non-salient machines with distributed windings. Both capacitances directly affect the BVR which has been recognized as an important parameter in estimating the likeliness with which a given electric machine may suffer from electric discharge machining bearing currents.

The proposed approach uses the simple analytic parallelplace capacitor equation and generic normalization functions derived from extensive parameter studies and electrostatic numerical analysis. The final expressions not only allow for the prediction of the stator-winding-to-rotor and rotor-toframe capacitances, in fact, they are also easily applicable; for example, the sensitivity of the BVR towards changes in the different stator slot parameters may be readily studied. Further studies applied to machines with different slot geometries will enhance the confidence in the approach. In addition, the method could be applied to machines with concentrated windings, as well.

(Remark: This paper expands upon preliminary results presented in [36] by significantly more experimental results and the related discussion.)

\section{REFERENCES}

[1] S. Chen, T. A. Lipo, and D. Fitzgerald, "Modelling of bearing currents ininverter drives," IEEE Trans. Ind. Appl., vol. 32, no. 6, pp. 1365-1370, Nov./Dec. 1996.

[2] J. Erdman, R. Kerkman, and D. Schlegel, "Effect of PWM inverters on AC motor bearing currents and shaft voltages," IEEE Trans. Ind. Appl., vol. 32, no. 2, pp. 250-259, Mar./Apr. 1996.

[3] D. Busse, J. Erdman, R. Kerkman, D. Schlegel, and G. Skibinski, "The effect of PWM voltage source inverters on the mechanical performance of rolling bearings," IEEE Trans. Ind. Appl., vol. 33, no. 2, pp. 567-576, Mar./Apr. 1997.

[4] D. Busse, J. Erdman, R. Kerkman, and D. Schlegel, "Bearing currents and their relationship to PWM drives," IEEE Trans. Power Electron., vol. 12, no. 2, pp. 243-252, Mar. 1997.

[5] D. Busse, J. Erdman, R.J. Kerkman, D.Schlegel, G. Skibinski, "System electrical parameters an their effects on bearing currents", IEEE Trans. Ind. Appl., vol. 33, no. 2, March/April 1997, pp. 577-584.

[6] S. Bell, T. J. Cookson, S. A. Cope, R. A. Epperly, A. Fischer, D.W. Schlegel, and G. L. Skibinski, "Experience with variable-frequency drives and motor bearing reliability," IEEE Trans. Ind. Appl., vol. 37, no. 5, pp. 1438-1446, Sep./Oct. 1998.

[7] H. E. Boyanton and G. Hodges, "Bearing fluting [motors]," IEEE Ind. Appl. Mag., vol. 8, no. 5, pp. 53-57, Sep. 2002.

[8] R. Schiferl and M. Melfi, "Bearing current remediation options," IEEE Ind. Appl. Mag., vol. 10, pp. 40-50, Jul./Aug. 2004.

[9] T. Plazenet, T. Boileau, C. Caironi, and B. Nahid-Mobarakeh, "A comprehensive study on shaft voltages and bearing currents in rotating machines," IEEE Trans. Ind. Appl., vol. 54, no. 4, pp. 3749-3759. Jul/Aug 2018.

(C) 2019 IEEE. Personal use of this material is permitted. Permission from IEEE must be obtained for all other uses, in any current or future media, including reprinting/republishing this material for advertising or promotional purposes, creating new collective works, for resale or redistribution to servers or lists, or reuse of any copyrighted component of this work in other works. https://doi.org/10.1109/TIA.2019.2898850 
[10] J. Ulrych, V. Mentlík, "Dielectric properties of sunflower, rapeseed and commonly used mineral oil," Proc. $17^{\text {th }}$ International Scientific Conference on Electric Power Engineering (EPE), pp. 1-4, 2016.

[11] Y. Gemeinder, M. Schuster, B. Radnai, B. Sauer, and A. Binder, "Calculation and validation of a bearing impedance model for ball bearings and the influence on EDM-currents," ICEM 2014, vol. 1, pp. 1804-1810, 2014.

[12] A. Furtmann, H. Tischmacher, and G. Poll, "Extended HF equivalent model of a drive train," ICEM 2016, pp. 2244-2250, 2016.

[13] R. Naik, T. A. Nondahl, M. J. Melfi, R. Schiferl, and J.S. Wang, "Circuit model for shaft voltage prediction in induction motors fed by PWM-based AC drives", IEEE Trans. Ind. Appl., vol. 39, no. 5, pp. 1294-1299, Sep./Oct. 2003.

[14] O. Magdun and A. Binder, "Calculation of roller and ball bearing capacitances and prediction of EDM currents", Proc. IECON'09, 3-5 Nov. 2009. pp. 1051-1056.

[15] V. Niskanen, A. Muetze, and J. Ahola, "Study on bearing impedance properties at several hundred kilohertz for different electric machine operating parameters", IEEE Trans. Ind. Appl., vol. 50, no. 5, 2014, pp. 3438-3447.

[16] W. Jacobs, R. Boonen, P. Sas, and D. Moens, "The influence of the lubricant film on the stiffness and damping characteristics of a deep groove ball bearing," Mechanical Systems and Signal Processing, vol. 42. nos. 1-2, pp. 335-350, 2016.

[17] A. Muetze and A. Binder, "Calculation of motor capacitances for prediction of the voltage across the bearings in machines of inverterbased drive systems, IEEE Trans. Ind. Appl., vol. 43, no. 3, May/June 2007, pp. 665-672.

[18] J. Park, T. Randima Wellawatta, S. Choi, and J. Hur, "Mitigation method of the shaft voltage according to parasitic capacitance of the PMSM", IEEE Trans. Ind. Appl., vol 53, no. 5, Sep./Oct. 2017, pp. 4441-4449.

[19] H. Tischmacher, I.P. Tsoumas, and A. Furtmann, "Extended probability model for discharge activities in the drive train of converter-fed electric motors," EPE-ECCE Europe 2015, 2015.

[20] M. Asefi and J. Nazardeh, "Survey on high-frequency models of PWM electric drives for shaft voltage and bearing current analysis" IET Electr. Syst. in Transp., 2017, vol. 7, Iss. 3, pp. 179-189.

[21] A. Muetze and A. Binder, "Don't lose your bearings," IEEE Ind. Appl. Mag., vol. 12, no. 4, pp. 22-31, Jul. 2006.

[22] E. Wittek, M. Kriese, H. Tischmacher, S. Gattermann, B. Ponick, G. Poll, "Capacitances and lubricant film thicknesses of motor bearings under different operating conditions", Proc. CEM 2010, 6-8 Sept. 2010, Rome, Italy.

[23] O. Magdun and A. Binder, "High-frequency induction machine modeling for common mode current and bearing voltage calculation", IEEE Trans. Ind. Appl., vol. 50, no. 3, May/June 2014.

[24] O. Magdun, Y. Gemeinder, A. Binder, and K. Reis, "Calculation of bearing and common-mode voltages for the prediction of bearing failures caused by EDM currents", SDEMPED 2011, 5-8 Sept. 2011, Bologna, Italy, pp. 462-467.

[25] K.B. Baltzis, "The finite element method magnetics (FEMM) freeware package: May it serve as an educational tool in teaching electromagnetics?", Educ. Inf. Technol. (2010), 15, pp. 19-36.

[26] H. Nishiyama and M. Nakamura, "Capacitance of a Strip Capacitor", IEEE Transactions on Components, Hybrids, and Manufacturing Technology, vol. 13, no. 2, June 1990, pp. 417-423.

[27] J. Adabi, F. Zare, A. Ghosh, and R.D. Lorenz, "Calculations of capacitive couplings induction generators to analyse shaft voltage, IET Power Electron., 2010, vol. 3, no. 3, pp. 379-390.

[28] O. Magdun, Y. Gemeinder, and A. Binder, "Prevention of harmful EDM currents in inverter-fed AC machines by use of electrostatic shields in the stator winding overhang," in IECON 2010, 7-10 Nov. 2010, Glendale, AZ, USA, pp. 962-967.
[29] M. Kriese, E. Wittek, S. Gatterman, H. Tischmacher, G. Poll, and B. Ponick, "Prediction of motor bearing currents for converter operation", in ICEM 2010, 6-8 Sept. 2010, Rome, Italy.

[30] H. Nishiyama and M. Nakamura, "Form and capacitance of parallel plate capacitors", IEEE Transactions on Components, Packaging, and Manu-facturing Technology - Part A, vol. 17, no. 3, September 1994, pp. 477-484.

[31] M.G. Say, "Performance and Design of AC Machines", Pitman, London, 1970.

[32] J. Pyrhönen, T. Jokinen, and V. Hrabovcova, "Design of Rotating Elecrical Machines", Wiley, 2009, ISBN: 978-0-470-74008-8.

[33] D. F. Busse, J. M. Erdman, R. J. Kerkman, D. W. Schlegel, and G. L. Skibinski, "An evaluation of the electrostatic shielded induction motor: a solution for rotor shaft voltage buildup and bearing current," IEEE Trans. Ind. Appl., vol. 33, no. 6, pp. 1563-1570, 1997.

[34] F. J. T. E. Ferreira, M. V Cistelecan, and A. T. de Almeida, "Evaluation of slot-embedded partial electrostatic shield for high-frequency bearing current mitigation in inverter-fed induction motors," IEEE Trans. Energy Convers., vol. 27, no. 2, pp. 382-390, Jun. 2012.

[35] B. Heidler, K. Brune, and M. Dobbelbauer, "Desing aspects of an electrostatic shield in an electric machine for hybrid electric vehicles", Proc. PEMD 2016, $19^{\text {th }}-21^{\text {st }}$ April, 2016, Glasgow, UK.

[36] J. Ahola, A. Muetze, M. Niemelä, and A. Romanenko, "Normalizationbased approach to electric motor BVR related capacitances computation," Proc. 2018 IEEE Applied Power Electronics Conference and Exposition (APEC), San Antonio, TX, 2018, pp. 2868-2874.

(C) 2019 IEEE. Personal use of this material is permitted. Permission from IEEE must be obtained for all other uses, in any current or future media, including reprinting/republishing this material for advertising or promotional purposes, creating new collective works, for resale or redistribution to servers or lists, or reuse of any copyrighted component of this work in other works. 